\title{
Influence of Type and Compositions of SCMs on Expansion of Mortar Bars from Alkali Silica Reaction
}

\author{
Chakkarphan Sangsuwan $^{\mathrm{a}}$ and Suvimol Sujjavanich ${ }^{\mathrm{b}, *}$ \\ Kasetsart University, 50 Pahoyothin Rd., Jatuchak, Bangkok 10900, Thailand \\ E-mail: achak_sn@hotmail.com, bfengsusa@hotmail.com (Corresponding author)
}

\begin{abstract}
The effect of different local pozzolans, as a supplementary cementitious material (SCM), on the expansion of mortar bar due to Alkali Silica Reaction (ASR) were reported in this paper. Accelerated test on specimens using local volcanic aggregates, rhyolite, was used to investigate and to compare the effects of fly ash (FA) and metakaolin (MK) on the suppression of the length change. In this study, three different percentages of FA, namely, 20, 35 and 50 and three of MK, namely, 10, 15 and 20 were used as cement replacement. The results at 14 days showed slight decrease expansions for $20 \%$ FA replacement of $0.073 \%$ but the lowest expansions were $0.025 \%$ and $-0.001 \%$, respectively for $35 \% \mathrm{FA}$ and $10 \% \mathrm{MK}$, compared to $0.176 \%$ of the control mix. Increase the SCMs to $50 \% \mathrm{FA}$ and 15 $20 \%$ MK yielded reduction of expansion to the innocuous level. Results from 28 days acceleration registered a slight increase in expansion for FA mixes of 35 and $50 \%$ and all MK mixes, but still less than $0.10 \%$, the threshold for innocuous level. Chemical composition analysis revealed decrease in $\mathrm{CaO} / \mathrm{SiO}_{2}$ and $\mathrm{CaO} / \mathrm{Al}_{2} \mathrm{O}_{3}$ ratio of the cementitious systems. This correlated with the expansion reduction. But alumina in $\mathrm{Al}_{2} \mathrm{O}_{3} / \mathrm{SiO}_{2}$ ratio showed the dominant effect on ASR suppression. Microstructures of all materials and casted specimens were also studied in detail. Considering all aspects, these SCMs, used in suitable amount were considered good candidates for ASR prevention in new concrete structures for both short and long term
\end{abstract}

Keywords: ASR expansion, fly ash, metakaolin, mortar bars, rhyolite.

ENGINEERING JOURNAL Volume 24 Issue 1

Received 12 October 2018

Accepted 1 November 2019

Published 8 February 2020

Online at http://www.engj.org/

DOI:10.4186/ej.2020.24.1.1 


\section{Introduction}

Different types of deterioration have been observed in many concrete structures. Among them, chemical deterioration, in particular alkali-silica reaction (ASR) has been of worldwide concern [1]. ASR is the chemical reaction between certain mineral forms found in some kinds of aggregate and alkali in cement. The resulting gel products expands upon imbibing surrounding moisture [2]. These cause internal cracks and loss of concrete integrity, mechanical properties, serviceability and durability of the impacted structure. However, this distress requires lengthy period before the results are noticeable. The wide variations of base materials both aggregates and cement and the complexity of the phenomenon are some of the difficulties faced by researchers of ASR $[3,4]$.

Almost eight decades ago since the first ASR evidence has been reported, researches have been conducted worldwide in many topics to understand the mechanisms involved with the objective of mitigation and prevention $[1,5]$. Many researchers have focused on prevention for new structures where the use of potential reactive aggregates is unavoidable $[2,6]$. The benefit of several pozzolans, used as supplementary cementing material (SCMs), in ASR control have been reported [7, 8].

Variations in effectiveness of expansion control of different pozzloans, including fly ash, have been reported $[8,9,10]$. Better results of class $\mathrm{F}$ fly ash in suppressing ASR expansion than those of the high $\mathrm{CaO}$ class $\mathrm{C}$ has been widely reported $[3,6]$.

The first report [11] on ASR occurrence in Thailand raised the concern on the lack of information on local materials, their behaviors in concrete and the measures for mitigation and prevention. Several sources of aggregate with ASR problem have been found locally, suggesting continuing ASR problems into the future [12].

Use of local fly ash in Thailand's construction industry typically focus on the economy, improving concrete properties as well as environment $[13,14,15]$, but not for ASR mitigation. A few work as a pilot study has been conducted on local materials, both fly ash and aggregates [16, 17 and positive results were reported. However, detailed information and understanding are essential for the prevention or mitigation measures.

The benefit of pozzolans on ASR alleviation has been deduced from the denser concrete microstructure from the pozzolanic reaction, the alkalinity reduction of the pore solution, the change in $\mathrm{CSH}$ and its alkali binding as well as reducing mass transport etc. [18, 19]. Several mechanisms affecting expansion control have received widening interests. Some works revealed the low $\mathrm{Ca} / \mathrm{Si}$ $\mathrm{CSH}$ from pozzolanic reaction benefits in effectively bound-alkali, compared to those of the higher ratio of typical hydration product [20]. The impact of the amount of used and chemical compositions of pozzolan on expansion reduction are also of interest [21, 22]. A few works indicated the influence of oxide of alumina in calcined clay such as meta kaolin (MK) on the change of ASR mechanism and expansion behaviors $[23,24,25,26]$.
The existence of high alumina and its impact on silica dissolution for ASR aspect and the consequent of expansion suppression have been of interests. However, the effect of the chemical compound in the system are still not clearly understood.

\section{Research Objectives and its Significance}

This paper focuses on the effectiveness study of two SCMs; moderate calcium oxide fly ash and metakaolin, in suppressing ASR induced expansion of local potentially reactive aggregates. Available information on moderate to high calcium oxide fly ash on ASR mitigation was less, probably because of the less effectiveness, compared to those of class $\mathrm{F}$ fly ash [16, 27]. However, utilizing available local material is essential in particular when these materials have already been used in concrete industry for other performance aspects [15]. The expected results may shed some ideas and provide the information on short and long term expansion and cracking due to the use of potential local reactive aggregates. Data from six different mixtures of two SCMs and the control were analysed, considering the changes in some chemical compounds of the system, about the concrete expansion due to ASR.

\section{Experimental Program}

\subsection{Materials}

Local aggregates and the two SCMs, namely fly ash, FA and metakaolin, MK were used throughout this study. Tests were conducted on binary blends; $(\mathrm{OPC}+\mathrm{FA})$, $(\mathrm{OPC}+\mathrm{MK})$ and the control. Expansion of specimens subjected to ASR acceleration were also evaluated and compared to those of the control mix.

\section{Aggregates:}

The rhyolite aggregates from the central part of Thailand, previously identified as a potentially reactive aggregates [12] were used. Rhyolite has been reportedly associated with the ASR occurrence in many concrete structures $[23,28,29]$. The chemical and mineral compositions of the aggregates were investigated and shown in Table 1 and Fig. 2. The graded crushed aggregates in accordance with the ASTM C1260-01 [30], were used to cast all specimens.

\section{Fly ash:}

The same lot of collected local fly ash was used throughout the study to avoid the variation of material. This FA has the chemical compositions as follows; total amount of $\mathrm{SiO}_{2} \mathrm{Al}_{2} \mathrm{O}_{3}$ and $\mathrm{Fe}_{2} \mathrm{O}_{3} 70.36 \%$, Cao 18.12\%, $\mathrm{SO}_{3} 3.55 \%$. The details are shown in Table 1. The high $\mathrm{Na}_{2} \mathrm{O}_{\text {equiv. of } 2.843 \%}$ was observed. The particles were of spherical shape with the mean diameter of 15-30 micron and total specific surface area of $2200 \mathrm{~cm}^{2} / \mathrm{gm}$ with the 
density of $2.34 \mathrm{~cm}^{2} / \mathrm{gm}$, The results of SEM-EDS analysis are shown in Figure 1(a) and 1(b) [31]. Star markings in (a) indicated the points with EDS analysis. The results of EDS around the star with the red border is show in Fig. 1(b). Since calcium oxide of this fly ash was moderate, different impact on expansion control from literature reviews has been expected.

\section{Metakaolin:}

Imported Metakaolin from Engelhard MetaMax Thailand was used. The chemical compositions are as follows: total amount of $\mathrm{SiO}_{2}, \mathrm{Al}_{2} \mathrm{O}_{3}$ and $\mathrm{Fe}_{2} \mathrm{O}_{3} 97.60 \%$, $\mathrm{CaO} 0.02 \%$, and $\mathrm{SO}_{3} 0.08 \%$, are shown in Table 1 . The very low $\mathrm{Na}_{2} \mathrm{O}_{\text {equiv. }}$ of $0.418 \%$ was observed. The flat, layered and flaky structure of the MK shown in Fig. 1(c). $\mathrm{MK}$ was of the average size of 1-2 micron and specific gravity of 2.50 .

\section{Cement:}

Commercially available ordinary Portland cement. Type-I, with chemical compositions and some properties, summarized in Table 1 was used. This cement had low alkali content (of $0.409 \%$ ) as suggested by many standards [32].

\subsection{Specimen Preparation}

Seven sets of mortar bars of $25 \times 25 \times 285 \mathrm{~mm}$ with embedded gage studs at both ends were casted. These composed of one control mix, and two mixes with SCM, fly ash $((\mathrm{OPC}+\mathrm{FA})$ and metakaolin $(\mathrm{OPC}+\mathrm{MK})$. Three FA percentages 20, 35 and 50 and three MK; 10, 15 and 20 were used. The details of these mixes with constant water to binder ratio (w/b) of 0.47 are shown in Table 2.

\subsection{Test Methods}

\section{Expansion test:}

Expansion measurements were performed on samples listed in Table 2. The accelerated mortar bar test (AMBT), according to ASTM C 1260 [30] and ASTM C 1567 [33] were conducted. Both standards are similar in the procedure, environment and criteria but not the purpose and materials. The ASTM C1260 investigates the ASR potential of aggregate of the control specimen, using Portland cement only. The second one aims for the deleterious potential of the combinations between SCMs and aggregate. This was used for the SCM specimens of cement with FA and with MK. Twenty four hours after casting, all specimens were demolded and kept in $80^{\circ} \mathrm{C}$ water for 24 hours before measuring the reference length. They were then immersed in $1 \mathrm{~N} \mathrm{NaOH}$ solution at $80^{\circ} \mathrm{C}$ for 14 days to accelerate ASR reaction. The duration also extended to 28 days to observe the long term expansion. Specimens were measured periodically every two days to 28 days.

Table 1. Chemical compositions of Type I cement, Fly ash, MK and ryholite [31, 34, 35].

\begin{tabular}{lccccccccccc}
\hline \multirow{2}{*}{ Oxide } & \multicolumn{10}{c}{ Chemical Composition, \% } \\
\cline { 2 - 13 } & $\mathbf{S i O}_{2}$ & $\mathbf{A l}_{2} \mathbf{O}_{3}$ & $\mathbf{F e}_{2} \mathbf{O}_{3}$ & $\mathbf{C a O}$ & $\mathbf{M g O}$ & $\mathbf{N a}_{2} \mathbf{O}$ & $\mathbf{K}_{\mathbf{2}} \mathbf{O}$ & $\mathbf{M n O}_{2}$ & $\mathbf{S O}_{3}$ & $\mathbf{L O I}$ & $\mathbf{N a}_{2} \mathbf{O}_{\mathbf{e}}$ \\
\hline Rhyolite & 56.49 & 17.39 & 6.51 & 8.55 & 3.02 & 2.69 & 4.03 & 0.16 & 0.04 & - & 5.341 \\
Cement & 18.74 & 5.22 & 3.20 & 65.30 & 0.82 & 0.08 & 0.50 & 0.06 & 2.80 & 2.75 & 0.409 \\
Fly ash & 36.35 & 19.86 & 14.15 & 18.12 & 2.82 & 1.33 & 2.30 & - & 3.55 & 0.55 & 2.843 \\
Metakaolin & 51.49 & 45.74 & 0.37 & 0.02 & $<0.00$ & 0.30 & 0.18 & - & 0.08 & - & 0.418 \\
\hline
\end{tabular}

\section{Results and Discussion}

Mineralogy investigation confirmed that the rhyolite composed of calcite, quartz, albite and feldspar as shown in Fig. 2 and Table 1. [35]. The XRD analysis revealed that the major mineral groups of crushed rhyolite composed of plagioclase $(70 \%)$, pyroxene $(10 \%)$ and opaque $(10 \%)$, and the minor compositions were calcite $(5 \%)$, olivine $(2 \%)$, chlorite $(2 \%)$ and epidote $(1 \%)$. The average phenocrysts consist of 0.05-3.0 mm in size. Plagioclase mostly showed zonal texture and lath shape. This rock type was widely reported as potentially reactive and previous local studied of this aggregates confirmed the ASR reactivity [1, 12]

From chemical investigation, $\mathrm{MK}$ had higher amount of $\mathrm{SiO}_{2}$ and $\mathrm{Al}_{2} \mathrm{O}_{3}$ than that of $\mathrm{FA}$. The XRD result in Fig. 1 (c) shows the broad hump at around $20^{\circ} 2 \theta$ angle indicating the amorphous phase of the materials [36]. 


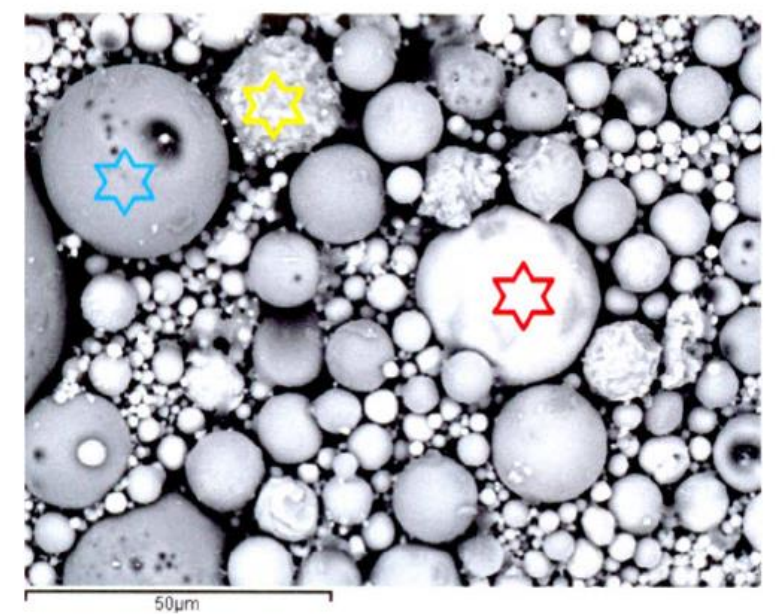

(a)

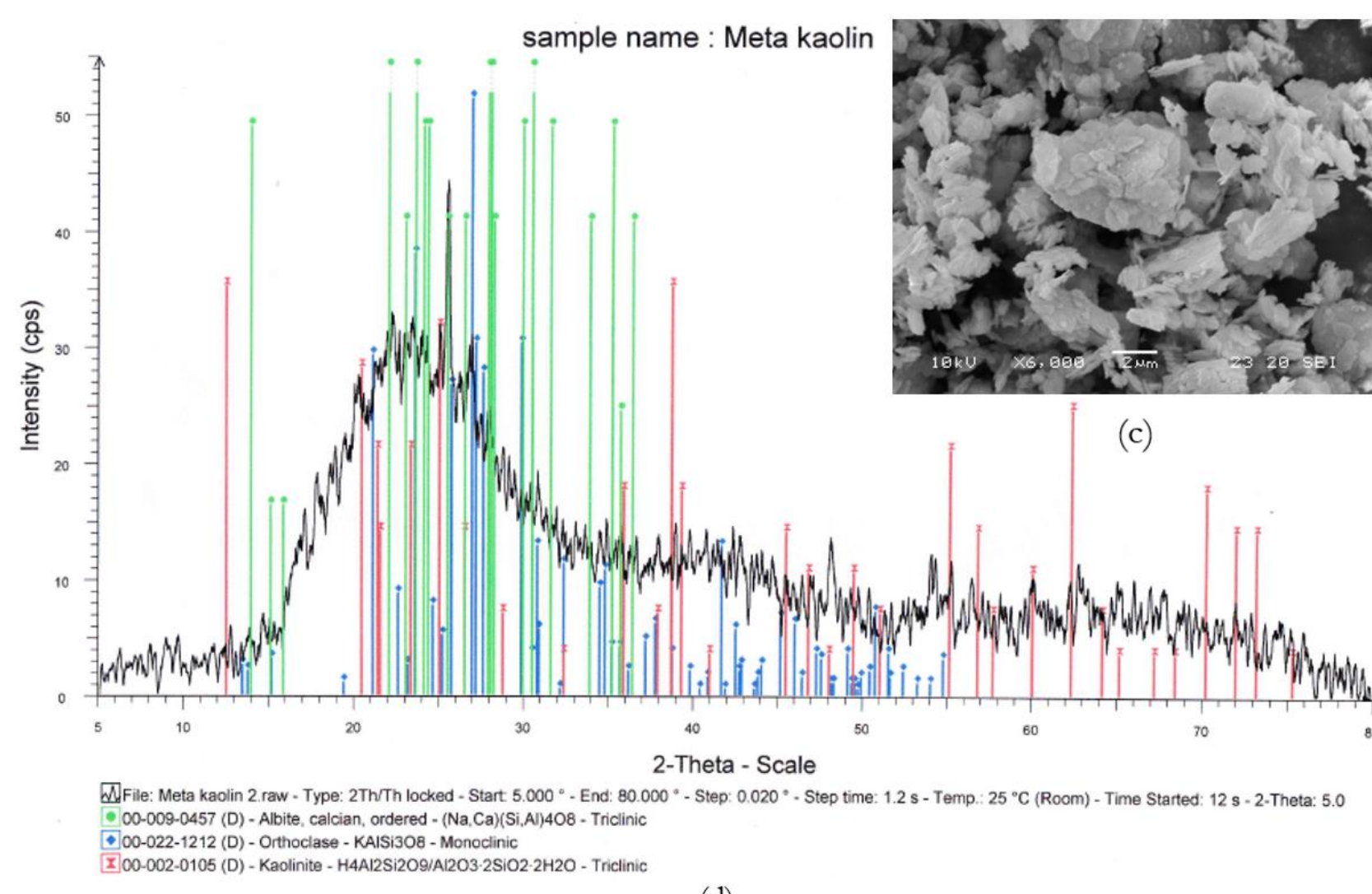

(d)

Fig. 1. (a) Round particle shape of fly ash; (b) the SEM-EDS analysis for chemical compositions; (c) Angular particle shape of meta kaolin; and (d) XRD analysis [31, 34]. 


\subsection{Aggregates Investigation}

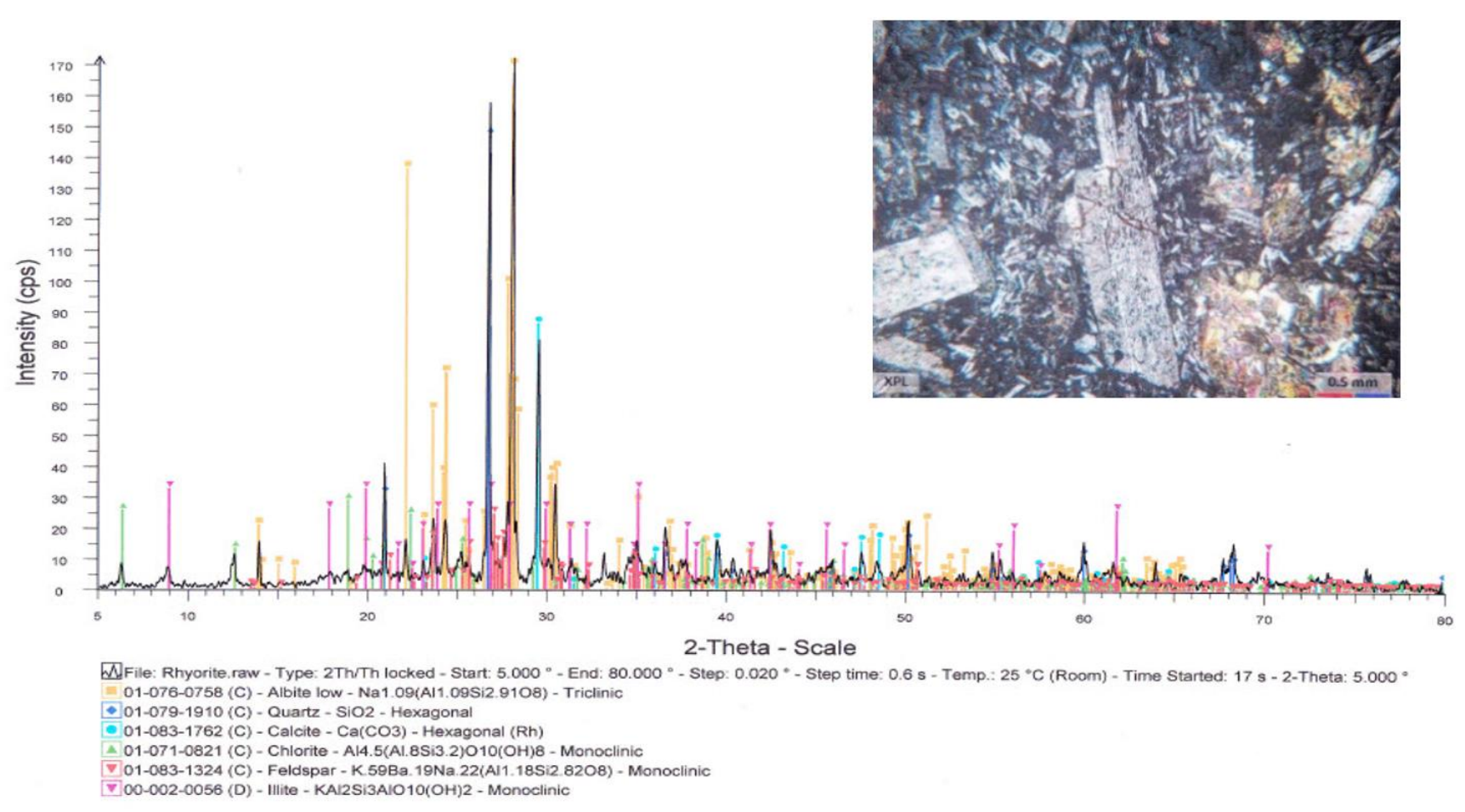

Fig. 2. XRD analysis of compositions and photo-micrograph of typical features of rhyolite aggregates [35].

\subsection{Accelerated Mortar Bar Test (AMBT)}

The average expansion of the control and the binary mixtures are shown in Table 2 and Fig. 3. At 14 days after acceleration, the expansion of control specimens $(\mathrm{M})$ was $0.176 \%$. This indicated the aggregates' reactivity. The measurement were made up to 30 day to observe the overall trend [30]. The expansion at 28 days was at $0.298 \%$ and continued to increase albeit at slower rate. The guideline suggests that expansion at 14 days of $0.20 \%$ or greater normally are indicative of potentially ASR deleterious expansion, and requires further study if it falls in the range of $0.1 \%-0.2 \%$ [30]. Several papers reported rhyolite as the fast reactive volcanic aggregates, but this local rhyolites appeared to be milder in reactive, most likely due to nature variation due to difference in aggregates sources $[1,12]$. The effect of low percentage of $\mathrm{Na}_{2} \mathrm{O}_{\text {equiv. }}$ in cement on expansion is not be clear in the high alkali environment of the accelerating test.

Although the 14 days expansion was not high, the continued expansion to almost $0.30 \%$ at 28 days, accompanied with the petrographic study, the aggregates in this study as ASR reactive. Expansion results of all binary mixes in Fig. 3 showed both MK and FA were effective. None of them produced the 14 days expansion larger than that of the $0.10 \%$ threshold. The 14 daysexpansion of $20 \%$ fly ash mixtures reduced to the innocuous level of $0.073 \%$. Although the 28 daysexpansion was high, no clear suggested value is available for consideration. The clear and significant reduction in expansion was observed when higher amounts was used, particular at $35 \%$ and $50 \%$ of cement replacement. The resulting expansion was (much less than $0.1 \%$ to almost zero or even slight contraction) for both at 14 and 28 days. The reduced expansion suggested that the combination of cement and FA, and aggregates were likely to produce acceptable expansion in concrete in long term [36]. These results agreed well with the others' work for class $\mathrm{C}$ high calcium content fly ash $[37,38]$. This may suggest the benefit of high amount of moderate calcium oxide fly ash in the high volume fly ash concrete (HVFA) when the aggregate was potentially reactive. It is of interest to observe that high alkali content of FA did not increase expansion with time on all FA mixture specimens. This could be due to the decreased alkali from SCM mixtures; the alkali binding effects of $\mathrm{CSH}, \mathrm{CAH}$ and the dense microstructure improvement $[25,39,40]$.

Compared to fly ash, metakaolin which has much lower alkali content was more reactive for ASR mitigation. With the small amount of $10 \%$ cement replacement the 14 days-expansion was reduced to innocuous level. Continued accelerated expansion slightly increased the 28 days-expansion to $0.063 \%$. This was the same order of magnitude achieved by using 35\% FA, a much higher percentage. The increased replacement by MK to $15 \%$ and $20 \%$ yielded the lowest values to almost no expansion at all. Slight shrinkage were also observed. These were probably caused by the increased finer pores of the specimens and the reduced expansion accompanying with the loss of surface-moisture from humidity/temperature 
changes during the measurement process. Similar to FA, the reduction of expansion was probably due to the lower alkali and dense microstructure, the larger alkali binding effect due to the higher reactivity as well as the effect form additional, alumina on the reduce dissolution rate of reactive phases in aggregates [41].

\subsection{Some Chemical Compounds' Ratios and their Effects on the Expansion of Mortar Bars}

The effects of available forms and amount of alumina, silica and calcium in the SCMs on the expansion of ASR samples have been of interests for several years. The additional $\mathrm{CaO}$ from different SCMs that was introduced into the system affected the expansion differently [38]. Of the same percentage of SCMs replacement, the samples with the low lime content yielded the lower expansion. This observation agreed well with Latifee's report on the correlation between lime content and the expansion of the samples with single SCM, fly ash from many different sources [38]. The higher lime content which reflected the lower content of other beneficial compounds, the higher expansion. However, other factors should be carefully considered such as the available active compounds like alumina and silica and its reactive form as well as the amount of replacement.

The plots of $\mathrm{CaO} / \mathrm{SiO}_{2}, \mathrm{CaO} / \mathrm{Al}_{2} \mathrm{O}_{3}$ ratio and $\mathrm{Al}_{2} \mathrm{O}_{3} / \mathrm{SiO}_{2}$, against expansion at different ages are shown in Fig. 4 and Fig. 5. Figure 4 shows the correlations between expansion at 14 and 28 days and both ratios of $\mathrm{CaO}$ to $\mathrm{SiO}_{2}$ and to $\mathrm{Al}_{2} \mathrm{O}_{3}$. This agreed with earlier reports $[20,41]$. The expansions of most specimens at longer time (28 days) show the higher correlation for both ratios. The higher correlation of alumina and silica on expansion was observed in Fig. 5. The lower slope of the inverse ratio of $\mathrm{Al}_{2} \mathrm{O}_{3}$ indicated the higher effectiveness of this oxide on suppressing expansion. The higher the ratio, the less the expansion. This could arise from the suppression of alumina on the dissolution of silica into the system.

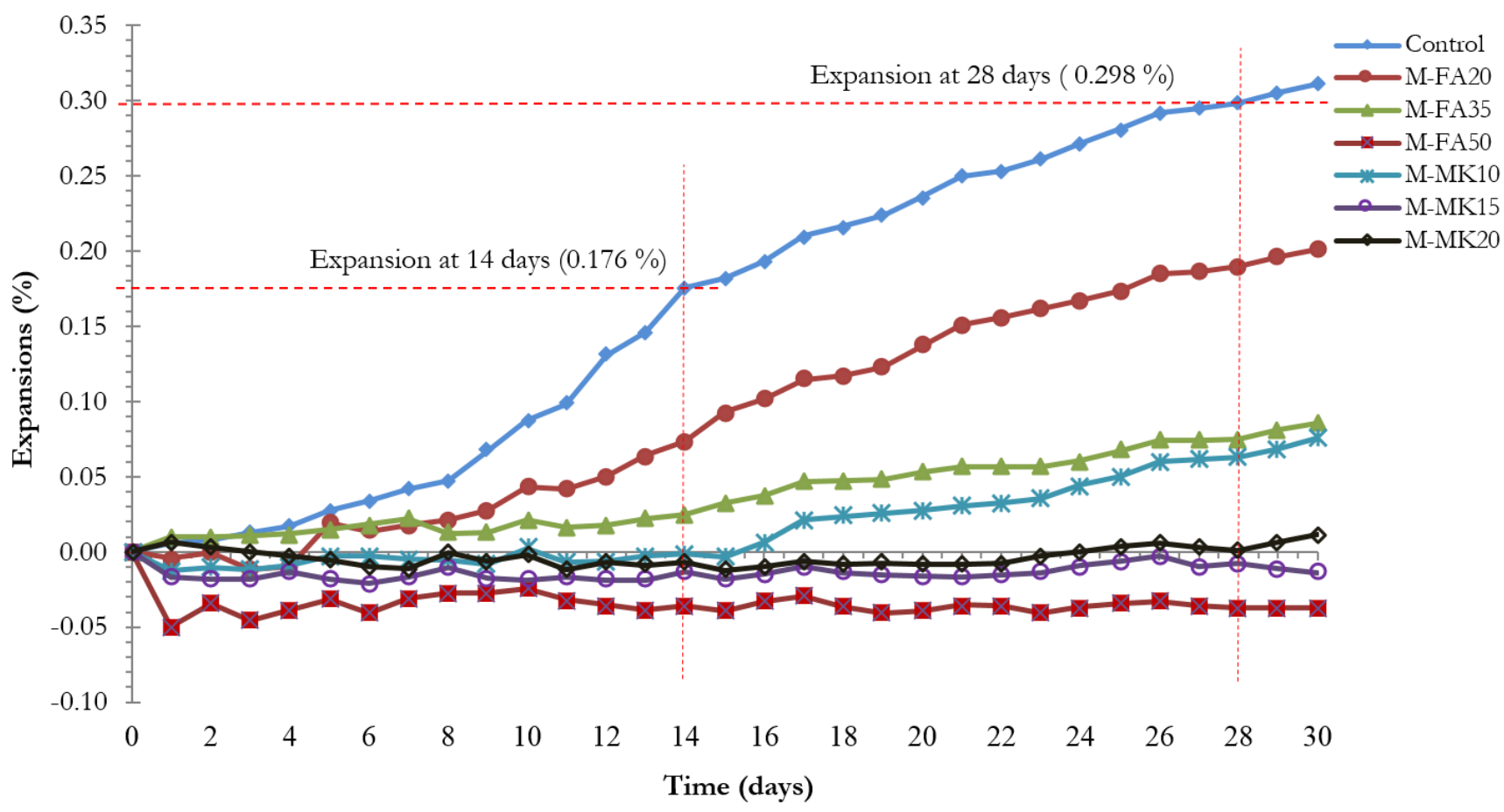

Fig. 3. Expansion with time of binary and the control samples.

Table 2. Some chemical compound ratios of the system and the corresponding expansion at different age of different SCMs samples (fly ash, FA; metakaolin, MK) and Control samples.

\begin{tabular}{clccccc}
\hline \multirow{2}{*}{ Item } & Mix Proportion & $\mathbf{C a O} / \mathbf{S i O}_{2}$ & $\mathbf{C a O} / \mathbf{A l}_{\mathbf{2}} \mathbf{O}_{\mathbf{3}}$ & \multirow{2}{*}{$\mathbf{A l}_{\mathbf{2}} \mathbf{O}_{\mathbf{3}} / \mathbf{S i O}_{2}$} & \multicolumn{2}{c}{ Expansions } \\
\cline { 6 - 7 } & & 3.485 & 12.510 & 0.279 & 0.176 & 0.298 \\
2 & M & 2.509 & 6.856 & 0.366 & 0.073 & 0.190 \\
3 & M/FA20 & 1.959 & 4.716 & 0.415 & 0.025 & 0.075 \\
4 & M/FA35 & 1.514 & 3.326 & 0.455 & -0.036 & -0.037 \\
5 & M/MK10 & 2.670 & 6.339 & 0.421 & -0.001 & 0.063 \\
6 & M/MK15 & 2.347 & 4.913 & 0.478 & -0.013 & -0.008 \\
7 & M/MK20 & 2.066 & 3.921 & 0.527 & -0.007 & 0.001 \\
\hline
\end{tabular}




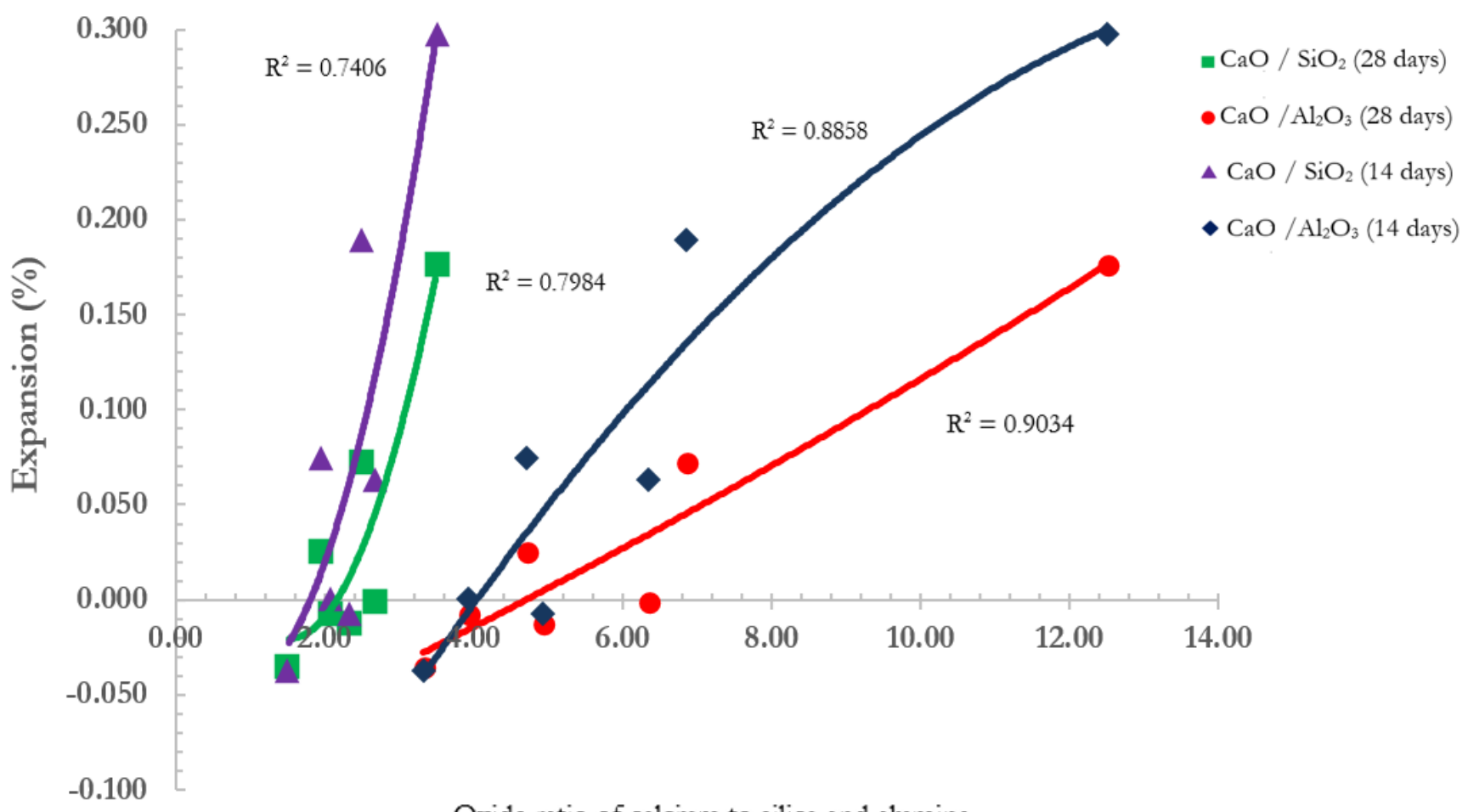

Fig. 4. Relationship of the $\mathrm{CaO}$ to $\mathrm{SiO}_{2}$ and to $\mathrm{Al}_{2} \mathrm{O}_{3}$ molar ratio to expansion at different ages.

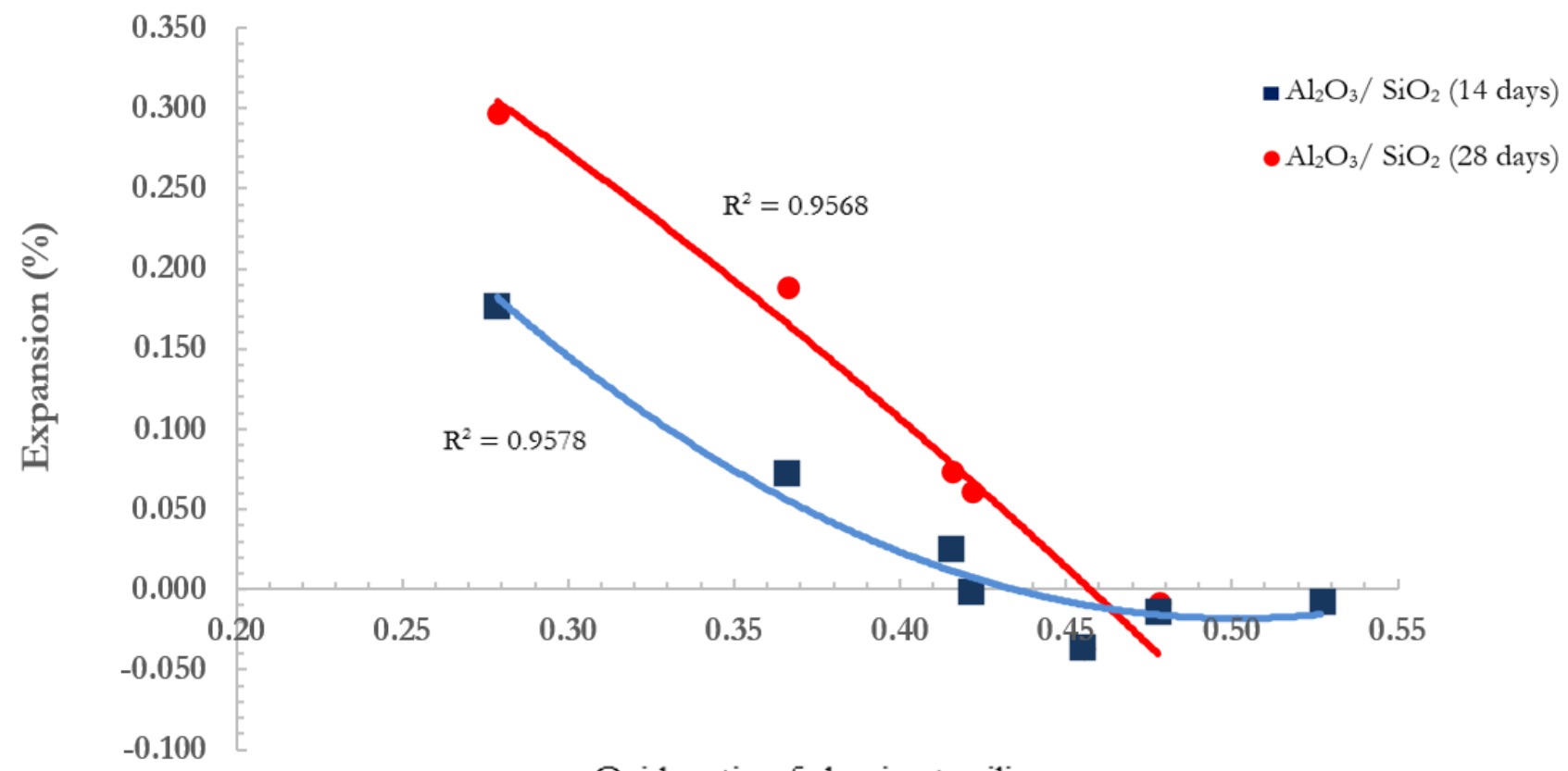

Fig. 5. Relationship of the $\mathrm{Al}_{2} \mathrm{O}_{3} / \mathrm{SiO}_{2}$ molar ratio and expansion at different ages.

\subsection{Petrographic Examination}

The details of polished thin section specimens from different mixtures- are shown in Fig. 6. The observed ASR reactive rim in the transition zone (ITZ) around the aggregates were clear features in the control specimens in $\mathrm{A}$ and $\mathrm{B}$, as indicated by red marks. Some cracks connected to other aggregates and a few crack filled with gel were observed in the paste as shown by arrows in A and B. In the sample with the small amount of SCMs, $20 \%$ fly ash, the evidence of ASR in the ITZ was scarce, but a few cracks filled with gel were observed in paste, as shown in the red circle and arrows, in C. 

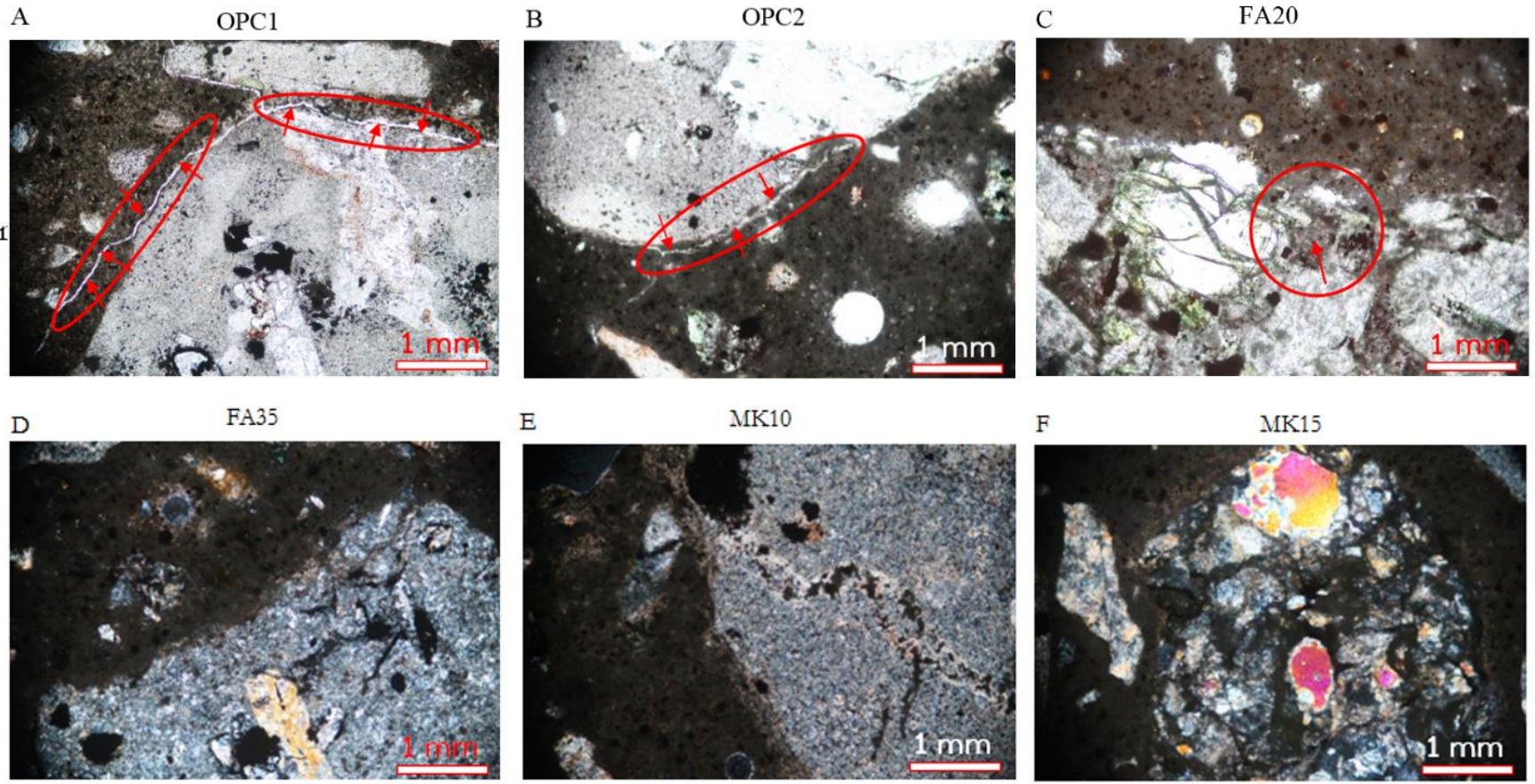

Fig. 6. Petrographic of polished Specimens and SCM specimens' sections under 10x stereomicroscope. ASR gel cracks are observed on specimens' sections in A\&B. Internal cracks are scarcely observed in FA20, FA35, MK10 and MK15 (in $\mathrm{C}-\mathrm{F}$, respectively).

However as the percentage of fly ash increased to $35 \%$ in D, or higher, cracks and ASR gel could not be visually observed. This was also similar to all MK sample (Figs. 6E-6F). From these finding, among two different SCMs, the rich alumina MK appeared to be more effective in ASR mitigation in term of reactivity and the smaller amount of use. Alumina compound in SCMs showed strong effect in expansion suppression.

\section{Conclusions}

In this study, it was found that type and compositions of SCMs clearly affected ASR expansion and the following conclusions were drawn:

(1) The local rhyolite was mildly reactive aggregate, having the accelerated expansion at 14 days of $0.176 \%$. The continued expansion to $0.298 \%$ at 28 days suggested the possibly innocuous in the acceleration test but may perform deleteriously in the field.

(2) Moderate calcium oxide lignite fly ash significantly reduced ASR expansion, especially when the cement replacement was $35 \%$ or higher, in both short and long term acceleration.

(3) Considering type and compositions of SCM, rich alumina and silica calcined clay was highly reactive and effectively reduced expansion in to innocuous level, even when small amount was used.

(4) Chemical composition analysis revealed that the reduction of $\mathrm{CaO} / \mathrm{SiO}_{2}$ and $\mathrm{CaO} / \mathrm{Al}_{2} \mathrm{O}_{3}$ ratios of cementitious systems significantly decreased expansion. But alumina showed more dominant effect than $\mathrm{SiO}_{2}$ on ASR suppression.

(5) The evidences from petrographic analysis clearly confirmed different effects of SCM materials.

(6) In this study ASR gel could not be visually observed in specimens with high fraction of FA and in all mixes with MK.

(7) In case when used of mildly reactive aggregates is unavoidable, used of the two SCMs can effectively reduce ASR expansion. The suggested percentage replacement for fly ash with less than $20 \%$ calcium oxide is of 35 . However, the effects on other required properties of concrete need to be considered. The low percentage replacement of rich alumino silicate MK; 10-15 is recommended for concrete mixture.

(8) Overall, FA and MK, used in suitable amount, were considered good candidates for prevention of ASR in new concrete structures in particular when being used in suitable amount.

\section{Acknowledgements}

This funding for this study was supported by the Kasetsart University Research and Development Institute. The supported materials, some information as well as some conducted test from Siam Research and Innovation Co., LTD. and CPAC Inc.Ltd, as well as a partial equipment support from Rajamangala University of Technology Phra Nakhon are greatly appreciated. 


\section{References}

[1] I. Sims and A. B. Poole, Eds., Alkali-Aggregate Reaction in Concrete: $A$ World Review. CRC Press, 2017.

[2] D. S. Lane, Alkali-Silica Reactivity in Virginia. Virginia Transportation Research Council, 1994.

[3] D. S. Lane and C. Ozyildirim, "Preventive measures for alkali-silica reactions (binary and ternary systems)," Cement and Concrete Research, vol. 29, pp. 1281-1288, 1999.

[4] D. Bulteel, E. Garcia-Diaz, C. Vernet, and H. Zanni," Alkali-silica reaction: A method to quantify the reaction degree," Cement and Concrete Research, vol. 32, no. 8, pp. 1199-1206, 2002.

[5] T. E. Stanton, Expansion of Concrete Through Reaction Between Cement and Aggregate. New York: American Society of Civil Engineers, 1940.

[6] S. Diamond, "Effects of two danish fly ashes on alkali contents of pore solutions of cement fly ash pastes," Cement and Concrete Resarch, vol. 11, no 3, pp. 383-394, 1981.

[7] A. Carles-Gibergues, M. Cyr, M. Moisson, and E. Ringot, "A simple way to mitigate alkali-silica reaction," Materials and Structures, vol. 41, no. 1, pp. 73-83, 2008.

[8] J. Zapała-Sławeta, "Alkali silica reaction in the presence of metakaolin-The significant role of calcium hydroxide," IOP Conference Series: Materials Science and Engineering, vol. 245, no. 2, p. 022020, Oct. 2017.

[9] K. E. Hanna, G. Morcous, and M. K. Tadros, "Effectiveness of class $\mathrm{C}$ fly ash on mitigating alkali-silica reaction in concrete pavement," International Journal of Construction Education and Research, vol. 5, no. 3, pp.167181, 2009.

[10] F. Bektasa, L. Turanli, T. Topal, and M. C. Goncuoglu, "Alkali reactivity of mortars containing chert and incorporating moderate-calcium fly ash," Cement and Concrete Research, vol. 3, no.4, pp. 22092214, 2004.

[11] S. Sujjavanich, P. Suwanvitaya, and D. Rothstein, "Investigation of ASR in mass concrete structuesA case study," in ISEC-6, Zürich, 2011.

[12] S. Sujjavanich, K. Won-In, T. Meesak, W. Wongkamjan, and V. Jensen, "Investigation of potential alkali-silica reactivity of aggregate sources in Thailand," International Journal of Geomate, vol. 13, no. 35, pp. 108-113, 2017.

[13] B. R. Hart, M. A. Powell, W. S. Fyfe, and B. Ratanasthien, "Geochemistry and mineralogy of flyash from the Mae Moh lignite deposit," Energy Sources, vol. 17, no. 1, pp. 23-40, 1995.

[14] P. Chindaprasirt, C. Jaturapitakkul, and T. Sinsiri, "Effect of fly ash fineness on compressive strength and pore size of blended cement paste," Cement \& Concrete Composites, vol. 27, pp. 425-428, 2005.

[15] S. Tangtermsirikul, "Development of fly ash usage in Thailand," in The International Workshop on Project Management, Kochi, Japan, March 2005, pp. 39-49.
[16] C. Sangsuwan and S. Sujjavanich, "Effects of moderate calcium oxide fly ash on expansion of mortar bar due to Thai local reactive aggregates," Engineering Journal, vol. 16, no. 3, pp. 101-108, 2012.

[17] S. Sujjavanich, K. Won-in, C. Lerksahakul, T. Thammapanont, S. Suwanpanasil, W. Wongkamchan, and H. Yokota, "Effect of fly ash type on ASR expansion of potential reactive aggregate," in The Thirteenth East Asia-Pacific Conference on Structural Engineering and Construction, Sapporo, Japan, September 2013, p. D-6.

[18] S. M. Shafaatian, A. Akhavan, H. Maraghechi, and F. Rajabipour, "How does fly ash mitigate alkali-silica reaction (ASR) in accelerated mortar bar test (ASTM C1567-04)," Cement and Concrete Composites, vol. 37, pp. 143-153, 2013.

[19] G. V. Walters and T. R. Jones, "Effect of metakaolin on alkali-silica reaction (ASR) in Concrete Manufactured with Reactive Aggregate," in Durability of Concrete, Second International Conference, August 4-9, 1991, Montreal, Canada, vol. II, pp. 941-954,

[20] B. Lothenbach, K. L. Scrivener, and R. D. Hooton, "Supplementary cementitious materials," Cement and Concrete Research, vol. 41, no. 12, pp. 1244-1256, 2011.

[21] M. H. Shehata, M. D. A. Thomas, and R. F. Bleszynski, "The effect of fly ash composition on the chemistry of pore solution," Cement and Concrete Reserach, vol. 29, no. 12, pp. 1915-1920, 1999.

[22] M. H. Shehata and M. D.A. Thomas, "The effect of fly ash composition on the expansion of concrete due to alkali-silica reaction," Cement and Concrete Research, vol. 30, no. 7, pp. 1063-1072, 2000.

[23] T. Chappex and K. L. Scrivener, "The influence of aluminium on the dissolution of amorphous silica and its relation to alkali silica reaction," Cement and Concrete Research, vol. 42, no. 12, pp. 1645-1649, 2012.

[24] J. Zapała-Sławeta, "Alkali silica reaction in the presence of metakaolin-the significant role of calcium hydroxide." IOP Conference Series: Materials Science and Engineering, vol. 245, pp. 1-8, 2017.

[25] T. Chappex, "The role of aluminium from supplementary cementitious materials in controlling alkali-silica reaction," doctoral thesis, École Polytechnique Fédérale De Lausanne, 2012.

[26] Z. Shi, C. Shi, J. Zhang, S. Wan, Z. Zhang, and Z. Ou, "Alkali-silica reaction in water glass-activated slag mortars incorporating fly ash and metakaolin," Cement and Concrete Research, vol. 108, pp. 10-19, 2018.

[27] E. Berry and V. M. Malhotra, Fly Ash in Concrete. Canada. Dept. of Energy, Mines and Resources, Canada Centre for Mineral and Energy Technology, 1986, p. 178.

[28] T. Chappex and K. L. Scrivener, "Alkali fixation of $\mathrm{C}-\mathrm{S}-\mathrm{H}$ in blended cement pastes and its relation to alkali silica reaction," Cement and Concrete Research, vol. 42, no. 8, pp. 1049-1054, 2012.

[29] D. S. Lane, "Combinations of pozzolans and ground, granulated, blastfurnace slag for durable hydraulic 
cement concrete," Virginia Transportation Research Council, Charlottesville, VA, 1999.

[30] Standard Test Method for Potential Alkali Reactivity of Aggregates Mortar-Bar Method, American Society for Testing and Materials, West Conshohocken, ASTM C1260-01, p. 5, 2003.

[31] Innovation and Technology Division, "Report for PFA analysis," Innovation and Technology Division CPAC Co. Ltd., Bangkok, Thailand, 2010.

[32] Standard Specification for Portland Cement, American Society for Testing and Materials, West Conshocken, ASTM C150-04, 2004. doi:10.1520/C0033-03A

[33] Standard Test Method for Determining the Potential AlkaliSilica Reactivity of Combinations of Cementitious Materials and Aggregate (Accelerated Mortar-Bar Method), American Society for Testing and Materials, West Conshohocken, ASTM C1567-04, 2004. doi: 10. 1520/ C1567-04

[34] Department of Geology, "Report X-Ray Fluorescence analysis Report," Faculty of Science, Chulalongkorn University, Bangkok, Thailand, 10 October 2012.

[35] Department of Geology, "Report X-Ray Fluorescence analysis Report," Faculty of Science, Chulalongkorn University, Bangkok, Thailand, 17 December 2012.
[36] A. Souri, F. Golestani-Fard, R. Naghizadeh, and S. Veiseh, "An investigation on pozzolanic activity of Iranian kaolins obtained by thermal treatment," Applied Clay Science, vol. 103, pp. 34-39, 2015.

[37] I. Fernandes, M. dos A. Ribeiro, M. A.T.M. Broekmans, and I. Sims, Eds., Petrographic Atlas: Characterisation of Aggregates Regarding Potential Reactivity To Alkalis. Springer, 2013.

[38] E. R. Latifee, "State-of-the-art report on alkali silica reactivity mitigation effectiveness using different types of fly ashes," Journal of Materials, vol. 2016, pp. 1-7, 2016.

[39] E. L'Hôpital, B. Lothenbach, K. Scrivener, and D. A. Kulik, "Alkali uptake in calcium alumina silicate hydrate (CASH)," Cement and Concrete Research, vol. 85, pp. 122-136, 2016.

[40] S. Y. Hong and F. P. Glasser, "Alkali sorption by $\mathrm{CSH}$ and CASH gels: Part II. Role of alumina," Cement and Concrete Research, vol. 32, no. 7, pp. 11011111, 2002.

[41] T. Chappex and K. L. Scrivener, "The effect of aluminum in solution on the dissolution of amorphous silica and its relation to cementitious systems," Journal of the American Ceramic Society, vol. 96, no. 2, pp. 592-597, 2013.

Chakkarphan Sangsuwan, photograph and biography not available at the time of publication.

Suvimol Sujjavanich, photograph and biography not available at the time of publication. 